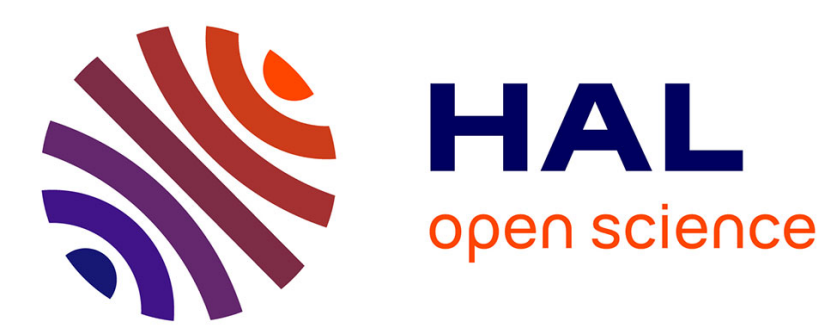

\title{
AN INTERPRETATION OF THE SHOCK HUGONIOT OF GRAPHITE
}

\author{
E. Wlodarczyk, R. Trebinski
}

\section{To cite this version:}

E. Wlodarczyk, R. Trebinski. AN INTERPRETATION OF THE SHOCK HUGONIOT

OF GRAPHITE. Journal de Physique IV Proceedings, 1991, 01 (C3), pp.C3-533-C3-538. 10.1051/jp4:1991375 . jpa-00250520

\section{HAL Id: jpa-00250520 https://hal.science/jpa-00250520}

Submitted on 1 Jan 1991

HAL is a multi-disciplinary open access archive for the deposit and dissemination of scientific research documents, whether they are published or not. The documents may come from teaching and research institutions in France or abroad, or from public or private research centers.
L'archive ouverte pluridisciplinaire HAL, est destinée au dépôt et à la diffusion de documents scientifiques de niveau recherche, publiés ou non, émanant des établissements d'enseignement et de recherche français ou étrangers, des laboratoires publics ou privés. 
Colloque C3, suppl. au Journal de Physique III, Vol. 1, octobre 1991

AN INTERPRETATION OF THE SHOCK HUGONIOT OF GRAPHITE

E. WLODARCZYK and R. TREBINSKI

Military Academy of Technology, 01-498 Warszawa, Poland

Résumé : Les particularités de l'Hugonoit de choc du graphite sont discutées par, le concept de l'isotherme-zéro-. La forme de la courbe isotherme est déduite des données expérimentales en se basant sur des considérations théoriques. Les conséquences dues à la forme de l'isotherme sur la détermination expérimentale de l'Huginot du choc sont mises en discussion.

Abstract - The peculiarities of the shock Hugoniot of graphite are discussed within the concept of the zero-isotherm. The shape of the isotherm is deduced from the experimental data on the ground of theoretical considerations. The consequences of the shape of the isotherm for the experimental determination of shock Hugoniot are considered.

\section{Introduction}

Numerous experiments established the shape of the shock Hugoniot of graphite shown on Fig.1. Peculiarities of the Hugoniot are interpreted as an evidence of the graphite - diamond polymorphous transformation. This interpretation is in contradiction to the results of recovery experiments. The amount of diamond in recovered after shocking graphite samples is very small $([1],[2])$. De Carli suggested in [3] that the formation of diamond necessitates higher temperatures, than obtainable in shocked graphite. De Carli's suggestion was confirmed by the analysis of conditions of dynamical synthesis of diamond $([4],[5],[6])$. Practically no diamond was obtained, when pressure and temperature were within the field, corresponding to the presence of peculiarities of the Hugoniot of graphite. Thus the question arises, how to interpret the peculiarities of the Hugoniot?.

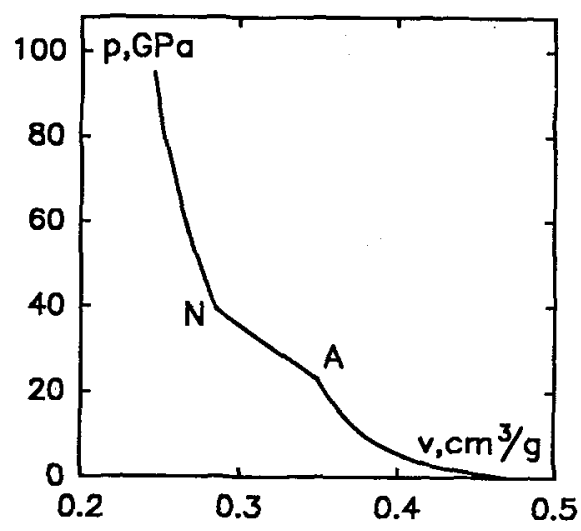

Fig.1.-The shock Hugoniot of graphite - [7]

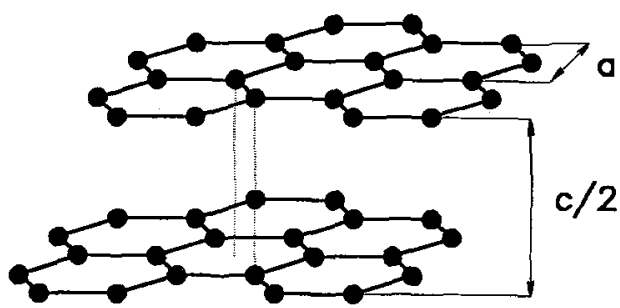

Fig.2.-A fragment of graphite lattice 


\section{Compression data for graphite and the zero-isotherm}

Peculiarities of the Hugoniot reflect characteristic features of the deformation process of the graphite lattice. A fragment of the lattice is shown on Fig.2. It is composed of flat, parallel layers, formed by atoms arranged in regular hexagons and bounded by strong, covalent bonds of $\mathbf{s p}^{2}$ type. Every second layer is in the equivalent position. Neighbouring layers are shifted on the one half of the hexagon great diagonal and bounded by relatively weak van der waals bonds. The heterogeneity of bonding determines the character of deformation. Radiographic investigations [8], [9] showed that graphite decreases its volume mainly due to the compression in the direction perpendicular to the layers (the $c$ direction). Changes with pressure of a and $c$ lattice constants are shown on Fig. 3 .

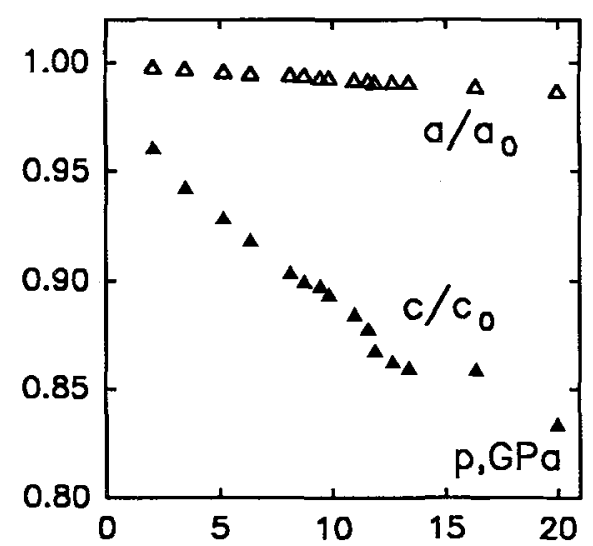

Fig.3. - The changes of $a$ and $c$ lattice constants with pressure - [9]

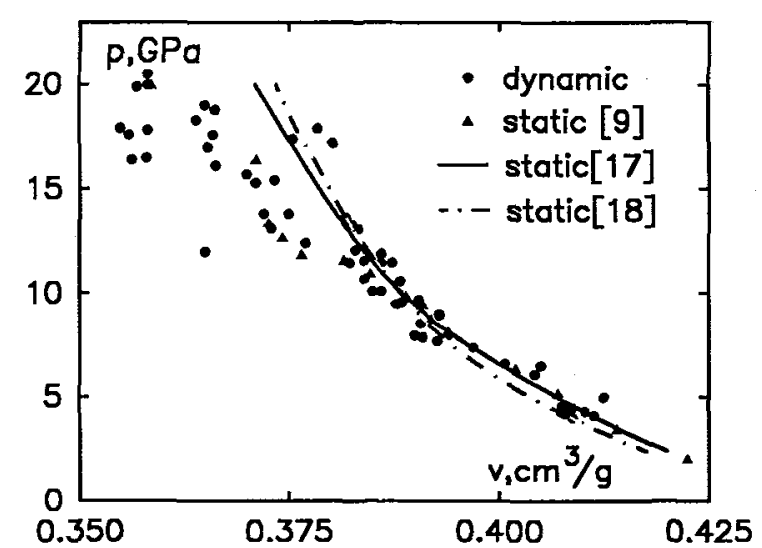

Fig.4.-Compression data for graphite: dynamic [7], [13]-[16], static $[9],[17],[18]$

The $c(p)$ curve has a throw at about $12 \mathrm{GPa}$. The throw reflects a change of the deformation mode. It is accompanied by dramatic changes of electrical and optical properties of graphite. A high increase of electrical resistivity at pressures 12-15 GPa was observed in [10]. A rapid decrease of the refractive index at $16 \mathrm{GPa}$ was recorded in [11]. with increasing pressure up to $26 \mathrm{GPa}$ the index becomes identical with the index of diamond. In [12] it was established that at 15-20 GPa graphite becomes transparent in the visible range. The position of spectral bands and the width of lines change but new lines do not appear.

Static and dynamic compression data for graphite also suggest a change in deformation mode at 12-14 GPa. These data are plotted on Fig.4. The static compression curves are an extrapolation from 0-10 $\mathrm{GPa}$ range. The results of dynamic experiments lay close to these curves up to $12 \mathrm{GPa}$. For higher pressures they are shifted left. The results of static experiments [9] behave in the same manner.

So as to establish the physical reason of aforementioned observations following facts should be taken into account. After loading-unloading procedure graphite loaded to $12 \mathrm{GPa}$ occurs to be the equimolar mixture of hexagonal and rhombohedral modifications - [9]. The great density of stacking faults in graphite shocked up to pressures less than $20 \mathrm{GPa}$ was observed by the authors of the monograph [19]. The formation of the rhombohedral modification from the hexagonal graphite loaded to $14 \mathrm{GPa}$ was detected in [20]. All these facts suggest, that at pressures higher than $12 \mathrm{GPa}$ the disintegration of the threedimensional order and formation of less symmetric sublattices due to the mutual shift of layers take place. The quantum mechanics calculations ([21]) showed, 
that the rhombohedral graphite is a semiconductor, while the hexagonal modification has metallic properties. This explains, while the decomposition of the hexagonal graphite is accompanied by dramatic changes of its electrical and optical properties.

The shift of layers facilitates further deformation, connected with the loss of the flatness of layers. This process was theoretically investigated in [21] and [22] on the base of modelling of the behaviour of the rhombohedral graphite (polytype $A B C$ ) and polytype $A A$ (all layers in the equivalent positions) elementary cells under compression. It was found that the first stage of compression is connected with oncoming of flat layers. At a certain degree of compression layers loose their flatness due to the deformation shown on Fig.5. It is accompanied by a decrease of the electron density between atoms in layers and an increase of the density between layers. The changes in the electron density facilitate further compression, because some bonds between atoms belonging to adjacent layers form.

The dependence of the cold energy of compression on the volume of elementary cell, found in $[21]$, can be use made of for calculation of the zero-isotherm $\mathrm{p}-\mathrm{v}$. This isotherm is shown on Fig.6 (plot 1). The presence of the inflection point $P$ can be attributed to the bonds forming between layers. Spontaneous transformation into diamond takes place, when the maximum point $M$ is attained. The maximum pressure 80 $\mathrm{GPa}$ is much higher than value, that can be deduced from the position of the upper bend of the Hugoniot (point $N$ on Fig.1) and the results obtained in [12] (it was observed in [12] that the changes of the optical properties over $35 \mathrm{GPa}$ are much slower than in the range 15-35 GPa). Thus we assumed $35 \mathrm{GPa}$ as the maximum pressure and constructed an isotherm fitting compression data in the 0-20 GPa range - plot 2 .
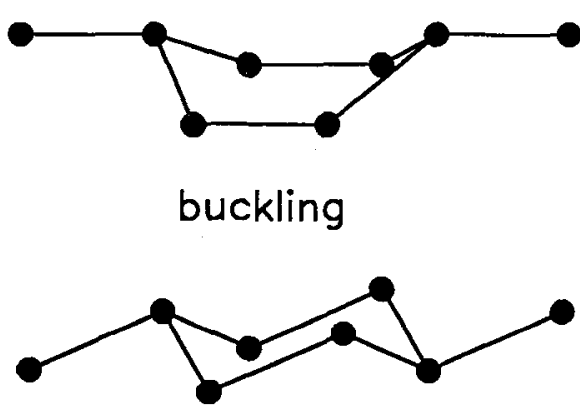

packering

Fig.5.Modes of deformation of layers

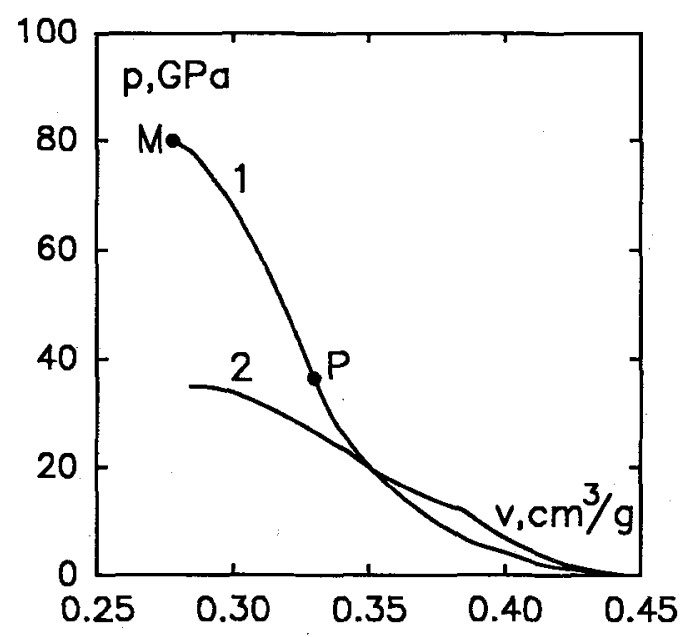

Fig.6.The zero-isotherms

\section{Zero-isotherm and shock Hugoniot}

If we neglect the thermal expansion of shocked material, the zeroisotherm and shock Hugoniot coincide. Let us consider the consequences of the shape of the Hugoniot shown on Fig.7. The Rayleigh line OA corresponds to a shock propagating in the porous sample of graphite with density $2.14 \mathrm{~g} / \mathrm{cm}^{3}$. The transformation to the dense modification is withstood by a potential barrier, that corresponds to the area of the figure AEM. This barrier can be overcome due to a supply of thermal energy in the course of shock compression. A part of this energy is the energy of vibrations in the c direction. The vibrations are accompanied 
by a turn of bonds in layers and a virtual increase of the electron density between layers. When the amplitude of vibrations is high enough, some bonds can form giving rise to the transformation. Because the amount of supplied energy depends on the amplitude of the shock, the influence of this thermally induced transformation on the dynamic compression data of graphite reveals itself only over a certain value of pressure $p_{A}$. It is obvious, that $p_{A}$ should decrease with decreasing the density of shocked material - [13] and its temperature -[23].

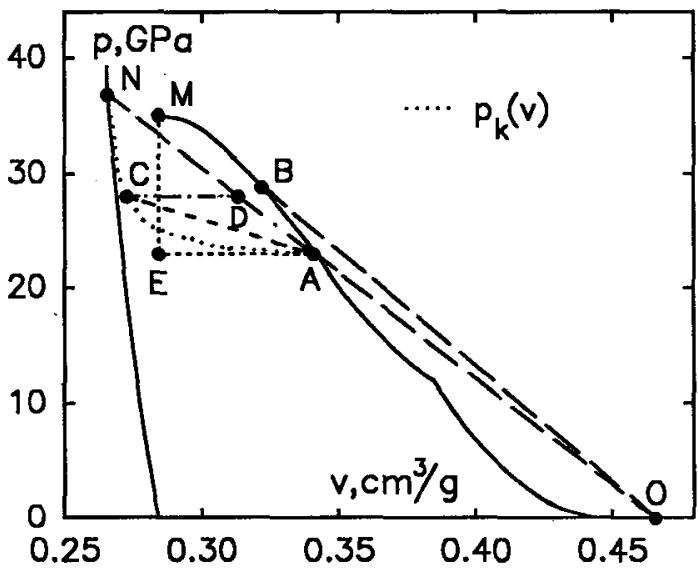

Fig.7.Shock Hugoniots of graphite and diamond

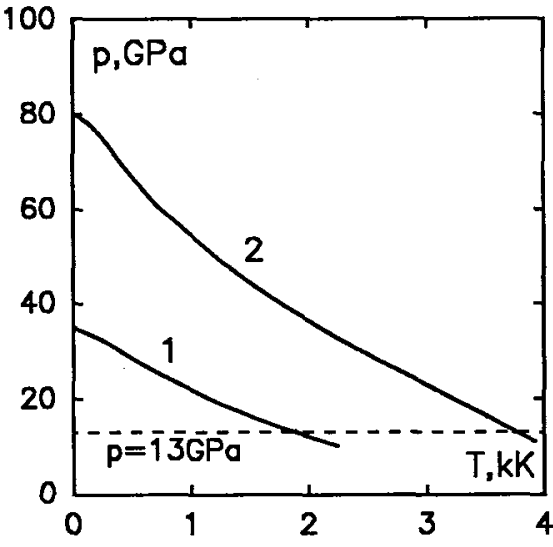

Fig.8. Curves of the energy of vibrations in the $c$ direction equal to the activation energy

Let us assume, that a shock with the amplitude $p_{B}>p_{A}$ has been generated in a graphite sample. For the thermal energy supply being higher than for $p=p_{A}$ and the potential barrier being lower, at least a part of the shocked material undergoes transformation. Rarefaction generated by the transformation weakens the shock and its amplitude decreases to $p_{A}$. The velocity of the shock decreases from $D=D_{B}$ to $D=D_{A}$, corresponding to the inclination of the $O A$ Rayleigh line. The decreasing of shock velocity in graphite samples was observed in [14] and [24], the decreasing of the amplitude - in [25]. Behind the shock the material transforms and its final state lies on a certain curve $p_{k}(v)$, that corresponds to the maximum degree of transformation at given pressure. The $p_{k}(v)$ curve shown on Fig.7 is a hypothetical curve, deduced from the results reported in [26].

In agreement with the theory two shock waves propagate in the sample: the first with the amplitude $\mathrm{p}_{\mathrm{A}}$ and the second, corresponding to the Rayleigh line AF. The concept of the double-wave configuration does not take into account, that small disturbances propagate with the frozen velocity of sound, that is coarsely determined by the slope of the isotherm in the point A. It can be seen from Fig.7, that this slope is higher than the slope of the AF Rayleigh line. Thus the second wave is unstable, for being subsonic in relation to the medium before its front. The real wave structure contains: shock with the amplitude $\mathbf{p}_{A}$, stationary transformation zone $A C$ and nonstationary transformation zone CF.

The experimental determination of the Hugoniot is based on measurements of the velocity of shock. It causes, that the points of the experimental Hugoniot over $p=p_{A}$ lie on the Rayleigh line $A N$. The intersection point of the diamond Hugoniot and this line $N$ corresponds to the upper bend of the experimental Hugoniot. The maximum value of $p_{N}$ can be appraised, by determining the intersection point of the Rayleigh line 
of graphite with the theoretical density tangent to the isotherm with the Hugoniot of diamond. The value $42 \mathrm{GPa}$ was obtained, being an upper bound of experimental values - 35-41 GPa. It follows from the above considerations that the AN section of the experimental Hugoniot is an apparent dynamic compression curve of graphite. It is determined by the conditions of experiment. In some investigations the section AN was obtained lying over the Rayleigh line $O A$. The reason is quite obvious, because the shock velocity determined on the finite base should be intermediate between $D_{A}$ and $D_{B}$.

Making use of the isotherm we can appraise the temperature $T$, at which at given pressure $p$ the energy of lattice vibrations in the $c$ direction is equal to the activation energy (the potential barrier). The share of the vibrations in the c direction in the whole thermal energy can be estimated on the base of the Krumhansl-Brooks model [27]. The curve $p(T)$ of the energy of vibrations in the c direction being equal to the activation energy of transformation is shown on Fig.8 (plot 1). It intersects the isobar $p=13 \mathrm{GPa}$ at $1900 \mathrm{~K}$, i.e. in the range of lonsdeileite synthesis - $1300-2300 \mathrm{~K}$ [28]. This fact suggests, that the isotherm corresponds to the graphite-lonsdeileite transformation. It explains, why so little amount of diamond was found in graphite recovered after shocking. The transformation graphite-londeileite is crystallographically reversible, so the reverse transformation takes place during the unloading process. An evidence of such a transformation is given in [24].

When calculating the $\mathrm{p}(\mathrm{T})$ curve for the theoretical isotherm with $\mathrm{p}_{\mathrm{M}}=80$ GPa, the curve 2 on Fig.8 is obtained. It intersects the isobar $13 \mathrm{GPa}$ at $3800 \mathrm{~K}, i . e$. in the range of the direct graphite-diamond transformation - 2800-4000K [28]. This fact is in agreement with Riter's conclusion ([29]), that the energy needed for packering (see Fig.5), that leads to diamond formation is three times greater than the energy needed for buckling, characteristic for lonsdeileite formation. Thus the theoretical isotherm based on the results published in [21] corresponds to the rhombohedral graphite-diamond transformation. It is worthwhile to notice, that the theoretical isotherm corresponding to polytype AA - lonsdeileite transformation determined in [22] is physically unrealistic, because packering instead of buckling as the deformation mode was assumed.

\section{Conclusions}

1. Static and dynamic compression data for graphite suggest, that its isotherm has the maximum at about $35 \mathrm{GPa}$. Approximate shape of the isotherm is shown on Fig.7.

2. The isotherm corresponds to the graphite-lonsdeileite transformation, that is energetically much more convenient than the graphitediamond transformation.

3. The experimental Hugoniot of graphite is in so-called "mixed phase region" an apparent compression curve depending on the conditions of experiment.

4. The double-wave configuration in shocked graphite is physically unreasonable.

5. Static and dynamic compression data suggest a presence of a cusp on the compression curve of the hexagonal graphite at about $12 \mathrm{GPa}$. It corresponds to disintegration of of threedimensional order and stacking faults formation in the whole volume of loaded material. This process can be described as a transformation of the hexagonal graphite into less symmetric and more compressible modifications. 


\section{REFERENCES}

/1/ De Carli P.S,Jamieson J.L,Science 133(1961) 1821.

/2/ Morris D.G,J.Appl.Phys. 51(1980) 2059.

13/ De Carli P.S,High Pressure Science and Technology, Vol.1, Physical properties and material synthesis, Plenum Press,NY-London 1977.

/4/ Cowan G.R, Dunnington B.W, Holtman A.H, US Patent 3401019 .

/5/ Balchan A.S, Cowan G.R, US Patent 3667911.

/6/ Deribas A.A, Staver A.M, Phys.Comb.Expl. (russ) 13 (1977) 477 .

17/ Gust W.H, Phys.Rev.B 22(1980) 4744.

/8/. Lynch R.W, Drickamer H.G,J.Chem. Phys. 44 (1966) 181.

19/ Yan Xiang Zhao, Spain J.L, Phys.Rev.B 40 (1989) 1951.

/10/ Bundy F.P, Kasper J.S, J. Chem. Phys. 46(1967) 3437 .

/11/ Haufland M, Syassen K, Sonnenshein R, Phys.Rev.B 40(1989) 1951.

/12/ Goncharov A.F, Macarenko I.N, Speshnov S.M, J.Exp.Tech. Phys. (russ) $96(1989) 670$.

/13/ Mc Queen R.G, Marsh S.P,Behaviour of dense media under high dynamic pressures, Gordon and Breach, New York 1968.

/14/ Dremin A.N, Pershin S.V,Phys.Comb.Exp1. (russ) 3(1968)112.

/15/ Doran D.G, J.Appl. Phys. 34(1963) 844 .

/16/ Coleburn N.I,J.Chem. Phys. 40(1964) 71.

/17/ Vereshchagin L.F. et al, Thermophys.High Temp. (russ) 15 (1977) 316 .

/18/ Andreev W.D,Malik W.R,Efimovitch L.P, Superhard Materials(russ) $2(1984) 16$.

/19/ Kurdiumov A.V.,Piliankevich A.N, Phase transformations in carbon and boron nitride(russ), Naukova Dumka, Kiev 1979.

/20/ Naka S. et al, Nature 259 (1976) 38 .

/21/ Fahy S, Louie S.G,Cohen M.L, Phys.Rev.B 34 (1986) 1191.

/22/ Fahy S, Louie S.G, Cohen M.L, Phys.Rev.B 35(1987) 7623.

/23/ Razorezov S.W, Kanel G.I, Ovchinnikov A.A, Detonation(russ), Chernogolovka 1981.

/24/ Alekseev Ju.L, Volkov K.V,J.Appl.Mech.Tech.Phys. (russ) 2 (1979) 105 .

/25/ Gogulia M.F,Batuchtin D.G, Voskoboinikov J.M, Lett.J.Tech.Phys. (russ) $13(1987) 786$.

/26/ Jugin Ju.N, Krupnikov K.K, Ovechkin N.Ja, Chem. Phys. (russ) $6(1987) 1447$.

/27/ Krumhansl J,Brooks H,J.Chem. Phys. 21(1953)1663.

/28/ Bundy F.P, US Patent 3488153.

/29/ Riter J.R,J.Chem.Phys. 52(1970) 5008 . 